\title{
Cause Analysis of Language Function of Implicit Coherence in English Discourse
}

\author{
Zhanyi He \\ College of Management, Changchun University of Chinese Medicine, Changchun, China \\ 229063980@qq.com
}

Keywords: Implicit coherence; Cause; Substitution; The Principle of Least Effort.

\begin{abstract}
Discourse cohesion and coherence is an important research field in contemporary text linguistics. Halliday and Hasan (1976) described common cohesive devices in English, such as substitution, repetition, ellipsis, etc. Later, many scholars put forward some new cohesive devices, such as implicit cohesion, register theory, etc. Based on recessivation of connectives in discourse, this paper explores the cause of implicit coherence in discourse from the perspectives of punctuations, pragmatic principles and cognition to provide references for further research in related field.
\end{abstract}

\section{Introduction}

Zhang Delu (2001) put forward the "implicit coherence" in Introduction of Cohesion in English of Halliday. His explanation of this linguistic phenomenon is that the coherence in discourse and context shows a certain degree of implicit characteristics, which can be called implicit coherence mechanism, including reference implicit coherence and ellipsis implicit coherence. Many scholars at home and abroad have also recognized this phenomenon and elaborated it from different perspectives. Lian Shuneng (1993) put forward parataxis in the "Contrastive Studies of English and Chinese", which is a preliminary description of implicit coherence. Cook (1994) proposed "the missing fallacy", which is the recognition of implicit coherence in cognition, and believes that the omission of conjunction does not affect the understanding of coherent discourse because people can automatically supplement the missing part. The "juxtaposition” proposed by Jiang Wangqi (2005) is to confirm the role and status of implicit coherence. It can be seen that Chinese and foreign scholars have only made a preliminary discussion and description of the role and working mechanism of implicit coherence in discourse, lack of in-depth research on the causes. Only Van Dyck clearly puts forward The Natural Order, and Zhang Delu also believes that implicit coherence is related to context.

In view of this, cause analysis of implicit coherence has important theoretical and practical significance. This paper attempts to explore causes of implicit coherence based on the recessiviation of subordinate conjunction.

\section{Substitution of punctuations}

The punctuation is an organic part of the written language and is an important auxiliary symbol subsystem for the language sign system. At the same time, punctuation in English is also an important part of the semantic framework. Its function does not merely indicate the pause of the sentence, the tone and the nature and role of the word, and some punctuation points also have the function of expressing semantics (Lu Zongfeng, 2002). And, as lexical semantic association, the semantic interpretation of punctuation in discourse can also be derived using semantic association. Randolph Quirk (1985) defines all English punctuation functions as two types: Separation and Specification. However, in the specific context, the semantic association of punctuation will also include the semantic connotation of the discourse. However, the semantic connotation of punctuation is inherently implicit (Lu Zongfeng, 2002). 
With the deepening of studies on punctuation, some scholars (Xu Ming, 2001) have further proposed that punctuation has a substitution function, that is, some punctuation substitute information transmitted by vocabulary and parallel connectives. The substitution of punctuation gives us the inspiration that punctuation has the same function of textual coherence. Some scholars (Sun Kun and Wang Rong, 2008) pointed out that punctuation can play a role of coherence, such as sequence, subordination, repetition, ellipsis, substitution, and double-reference. Therefore, punctuation, like connectives, can reveal semantic relationships between sentences, and are also important means for the logical coherence of texts. When expressing a logical relationship, you can choose to use punctuation or use connectives. When constructing a discourse, punctuations substitute connectives to make the recessivation of connectives to be implicit coherence.

Ex.1 The society was agreeable; many of her old friends and acquaintances were at the bay.

The role of the semicolon in the example 1 is to substitute the subordinate connective "because" to connect the two sentences and express the causal logic.

Ex.2 She asked him how often he heard from home, whether he had enough blankets on his bed, how much milk he drank a day.

In the example 2, the comma is used to enumerate a series of parallel clauses. Its usage is equivalent to the parallel conjunction "and", which makes the sentence concise, with fast rhythm.

Ex.3 Wallace knew that a small mistake could kill her: if he hit a vital organ, she would die.

The role of the colon in the example 3 is to introduce an explanation or to summarize, with the same meaning and effect as "that is".

\section{Consensus of logical presupposition}

Presupposition is an important proposition in the study of language logic. German contemporary scholar Bussmann.H (2000) defines presupposition as "(presupposition) is a self-evident (implicit) setting about the meaning of expression or discourse." Presupposition is the attachment of meaning to the basic meaning of the sentence. The presupposition of expression or discourse must be known to both the speaker and the listener. In short, presuppositions are things that the communicating parties need not to say and accept together in the process of communication. They have mutual knowledge (Fanli, 2006). At the same time, the presupposition is objective, regardless of whether the speaker and listener ignore or distort, the presupposition always exists objectively in the discourse.

Research shows that the mutual knowledge of presupposition plays an important role in the process of language communication. Both sides of the communication omit the components of mutual knowledge, making the communication activities more economical and coherent, but the meaning of the discourse is still very clear and complete, and the communication activities are not affected at all.

Logical Presupposition is a type of presupposition. It is the presupposition of a sentence, and the role is that the logical presupposition of the previous sentence can derive the logical relationship proposition of the second sentence directly. The previous sentence is a direct statement, which directly shows the logical relationship and forms the logical presupposition for the next discourse. The logical connective of the latter sentence becomes implicit, and the logic relationship between the two sentences is implicitly expressed in the form of omission.

Ex.4 Because he is ill, he is absent today.

Ex.5 Although it was cold, he went out without a coat.

In the example 4 and 5, the speaker first puts forward the presupposed facts "he is ill" and "it was cold", and used the subordinate connectives "because" and "although" to create logical presupposition. Therefore, the upcoming causal relationship or the adversative relationship becomes the psychological expectation of the listener. The reader automatically derives the causal or adversative logical relationship, thus omitting the explicit logical connectives and becoming implicit coherence. 


\section{Pragmatic optimization of the Principle of Least Effort}

The Principle of Least Effort, also known as the Economy Principle, is a fundamental principle that guides human behavior, that is, exchanges the maximum return with the minimum cost. From the perspective of language use and language communication, the Principle of Least Effort promotes the optimization of speech information, regulates language use, and achieves pragmatic optimization. In speech communication, the optimization of the Principle of Least Effort means that the speaker should use the simple language as far as possible to ensure the best communication effect; when the listener interprets the discourse, he or she can infer the meaning based on the existing experience and information to interpret the communicative intention of the speaker. For example, when describing the situation where a thief named Carl enters a museum, people tend to prefer the sentence (1) in terms of actual description and interpretation.

(1) Carl didn't know much about arts. He couldn’t choose.

(2) Carl didn't know much about arts, because he had poor knowledge about arts.

Therefore, when facing so many arts on the shelves and floors, he couldn't choose.

The economical language saves the time of communication, improves the efficiency of communication, and satisfies the need for least effort for both parties to communicate. Based on the pragmatic optimization of the Principle of Least Effort, not only unnecessary connective words can be omitted to become implicit, and even some unnecessary sentences can be omitted on the premise of not causing misunderstanding of the meaning.

\section{Discourse control of cognitive context}

Discourse is the product of social communication, and communication takes place in certain situations. When analyzing discourse, it is necessary to consider the effects of the content, participants, and communication channels of the communicative activities, which work together to form a situational configuration, called the Context of Situation. Context of situation plays a very important role in social communication and directly influences the generation and interpretation of discourse. Due to the constraints of context of situation, discourses that sometimes seem incoherent, with no internal cohesion, or sparse internal cohesion in certain contexts. For example,

A: Shall we go and get some ice cream?

B: I'm on a diet. How about other snacks?

A: Oh, okay.

By "I'm on a diet", B indicates the reason for refusing A's proposal, and the explicit connective "because" for the cohesion does not have to appear.

Knowledge or experience of people in the content and structure of the language or discourse used on different occasions constitute the cognitive context of discourse, which can restrict the language use and discourse generation of communicative activities, and also help readers or listeners to interpret incoherent discourse in the form.

Take the expository writing as an example. As a widely used genre, the exposition writing explains the feature, nature, status, or occurrence, development, and results of matters. The most important genre feature is the concise language and the most common content is the objective description of the development of matters. In the narrative, usually in chronological or logical order, that is, the natural order of Van Dyck, constituting the genre potential. In the same way, readers use the knowledge of cognitive context to supplement the complete default information and correctly derive the implicit information of the author or speaker. For example 6 ,

Ex. 6 There are three kinds of book owners. The first has all the standard sets and best-sells -unread, untouched. The second has a great many books -- a few of them read through, most of them dipped into. The third has a few books or many -- every one of them loosened by continual use.

The discourse describes three different attitudes towards the collection of books. There are no explicit connectives in the text. However, with the knowledge of cognitive context, the reader can still grasp the clear logical relationship. 


\section{Conclusion}

With regard to the cohesion and coherence of discourse, scholars have paid more attention to the study of explicit coherence devices as a sign and basis for the coherence of discourse. The introduction of implicit coherence and implicit coherence mechanism has opened up a new perspective for the study of discourse coherence, and has a certain positive significance for studying and understanding language functions and human brain mechanisms. This paper only discusses the causes of the functional ellipsis of subordinate connectives in implicit coherence, and introduces the four aspects that cause implicit coherence. Of course, we believe that the implicit coherence in the discourse is not simply caused by a certain function introduced in the paper. The various factors not work in a parallel manner, but affect or dominate information configuration in the discourse in close relationship, which is the result of a combination of multiple functions in context.

\section{Acknowledgements}

Fund program: Administration of Traditional Chinese Medicine of Jinlin Province Program: Theoretical research and practical exploration of English translation of traditional Chinese medical classics, Program No. 2017172.

\section{References}

[1] Cook, G. 1994. Discourse and Literature. Oxford University Press.

[2] Fauconnier, G. 1997. Mappings in Thought and Language. Cambridge: Cambridge University Press.

[3] Halliday, M. A. K. \& Hasan, R. 1976. Cohesion in English. London: Longman Group Limited.

[4] Halliday, M. A. K. \& Hasan, R. 1985. Language, Context and Text. Victoria: Deakin University Press.

[5] Quirk, R.C. \& Greenbaum, S. 1985. A Comprehensive Grammar of the English Language. London: Longman.

[6] Van Dijk, T.A. 1977. Text and Context: Explorations in the Pragmatics of Discourse. London: Longman.

[7] Van Dijk, T. \& Kintsch, W. 1983. Strategies of Discourse Comprehension. New York: Academic Press.

[8] Bussmann H. (Germany), 2000, Routledge Dictionary of Language and Linguistics, Foreign Language Teaching and Research Press.

[9] Fan Li, 2006, The Logical Definition, Nature and Function of Presupposition, Journal of Hunan First Normal College, No. 4.

[10] Jiang Wangqi, 2005, Mere Juxtaposition Is also a Cohesive Device, Foreign Languages in China, No. 2.

[11] Lian Shuneng, 1993, Contrastive Studies of English and Chinese, Higher Education Press.

[12] Lu Zongfeng, 2002, The Function of Punctuation, Journal of Southeast Guizhou National Teacher's College, No.1.

[13] Sun Kun, Wang Rong, 2008, New Exploration of Cohesion Function of Punctuations in Discourse, Theoretical Linguistics Research, Vol. 2, No. 1.

[14] Xu Ming, 2001, Substitution: The Third Function of English Punctuations, Foreign Language Teaching and Research, No. 5.

[15] Zhang Delu, Liu Rushan, 2003, The Development of the Theory of Text Coherence and Cohesion and Its Applications, Shanghai Foreign Language Education Press. 